\title{
Web 2.0 Technologies and its Application: A Study of Management Science students DAVV, Indore, M. P.,
}

\author{
Preeti Shrivastav, Dr. Kishor John, \\ ${ }^{I}$ PhD Research Scholar, Bhagwant University Ajmer, Rajasthan \\ ${ }^{2}$ Assitant Professor LIS, OSD, Higher Education, Indore (M.P.)
}

\begin{abstract}
Such as blogs, wikis, RSS feeds, social networks, Streaming Media and Instant Massaging etc. These tools and technologies are very useful for library and information services. This paper specially made to look into the applications of Web 2.0 in Libraries and Information Services and to suggest best applications which can be included as a support to provide these services. The analysis in this research is based upon previous researches and our own experimentation on Web 2.0 tools. The goal is to determine the Web 2.0 application, possible Uses and how libraries provide better services to its users. At the same time growth rate of use of Web 2.0 tools is increasing among student. So the present study will focus on the experience of university students. The study is conducted among the student of management studies in DAVV Indore.
\end{abstract}

Key word: Internet, Web 2.0.

\section{Introduction}

The term Web2.0 refers to the development of online services that encourage collaboration, communication and information sharing. It represents a shift from the passive experience of static "read only" web pages to the participatory experience of dynamic and interactive web pages. In other words, Web2.0 reflects changes in how we use the web rather than describing any technical or structural change. When Web 2.0 tools used in libraries, libraries provides more facility and more services to their users at their doorstep. Ultimately, blogs and wikis are relatively quick solutions for moving library collections and services into Web 2.0. Web2.0 services have been integrated within our organization, feedback from our members Web2.0 services are increasingly becoming implanted in many areas of life as more teenagers identify and attach these powerful contact tools. Similarly, libraries and librarians all over the world are using Web2.0 technologies to promote services, share information, and connect with users and network with classmates, on a global scale.

\section{Problem Statement}

The popularity of internet and web 2.0 tools is increasing among the educated people especially youth in collage and universities. Study observed that the internet and web 2.0 tools has very deep influence in the socio cultural life of the people as well as behavior of youth. There are many study conducted but no large scale research has been conducted on these issue. Some study is there but it does not focus on the student community. At the same time growth rate of use of Web 2.0 tools is increasing among student. So the present study will focus on the experience of university student of Management Science studies in DAVV Indore.

\section{Review of Literature}

Patel, Preeti and John, Kishor (2013)- Authors have discussed in their study that Social network sites (SNSs) become more popular in new generation. It provides interaction facility to its users. Interaction with internet is a great facility to the users. In this introductory article, we describe the history; services provided by the SNSs and examine the use of SNSs by the students. Study also observes the reason for using SNSs and problems faced by the students while using SNSs by the students. Personal information easily searched by any one is the most effecting factor for using SNSs. This article covers various aspects of SNSs. ${ }^{1}$

Musthafa. K (2012) - Says in his study the social networking experience of university student in India. The objective of the study was found out the use of Face book by the student of Aligarh Muslim University, India and to explore how and why they use face book. Time spent on face book and satisfaction level of student has been investigated. An Attempt has been done to determine the problem faced to use SNSs ${ }^{2}$.

Sahi, V. S. and Veena kumari (2012) - They discuss the role of web 2.0 technologies and Social Networking in libraries and also the possible use and benefit of the web 2.0 technologies in improving the customer services in library. The paper reports on survey of library professional and library users in Dhanvantri Library. Using web 2.0 and social networking for the benefit of the students, scholars and teachers ${ }^{3}$. 
Aqil, Mohammad \& Ahmad, Parvez (2011) - The objective and scope of this paper is to assess and highlight the potential of Web 2.0 in the context of libraries. The concept of Web 2.0 such as social networks, RSS feeds, blogs, streaming media, podcasts, Wikis, tags, mashups, etc. is defined and the possible applications in various library functions and activities are mentioned. ${ }^{4}$

Soni, Gautam \& Verma, Neeraj (2010) - This paper aims to discuss the concept of web 2.0, its characteristics, tools (blogs, wikis, RSS feeds, social networks, podcasting, tagging and Instant Massaging etc.) and possibilities to incorporate these tools and technologies in library and information services. It focuses on transformation of library services from Web 2.0 to Library 2.0 and the role of Librarian 2.0 in digital environment. ${ }^{5}$

Weber, Sebastian \& Rech, Jörg (2009) - They Discuss the Web 2.0 is a popular term used to describe a class of Web applications that offers mostly free services to its users. However, an exact definition of the concepts, features, and technologies that argue for a Web 2.0 service is still missing. Similarly, terms such as Web 3.0, Web 4.0, or Web 2.5 also have no clear and unambiguous definitions. ${ }^{6}$

Xiao, Norah (2008) - Various Web 2.0 technologies such as a blog, tags, YouTube, RSS feeds, Instant Messaging, online presentation have been selected to overcome challenges in the current library framework and to enhance the effectiveness of the approaches. These Web 2.0 technologies function as catalysts which help lower human barriers between my users and me, enable me to reach my users virtually, and attract users to resources from the library as well as various services. ${ }^{7}$

Birdsall, William F. (2007) - The current discussions on Web 2.0 development represent a significant development in the continuing interaction of technological developments and communications rights. In this paper the social movement for a right to communicate and the discourse surrounding Web 2.0 development are compared to demonstrate how Web 2.0 is a manifestation of an ongoing interaction between this human rights social movement and communication technology ${ }^{8}$.

Maness, Jack M. (2006) - The paper applies the theory and definition to the practice of librarianship, specifically addressing how Web 2.0 technologies such as synchronous messaging and streaming media, blogs, wikis, social networks, tagging, RSS feeds, and mashups might intimate changes in how libraries provide access to their collections and user support for that access ${ }^{9}$.

\section{Objectives of the Study}

The purpose of research is to discover answer to questions through the application of scientific procedure. For this following objectives have been created:

1. To find out the use of internet and web 2.0 tools by the Management students of the Devi Ahilya Vishwavidhyalaya Indore;

2. To find out the use of internet by the student for study purpose.

3. To find out the use of Web 2.0 tools for knowledge sharing.

4. To explore the purpose of using internet and web 2.0 tools.

5. To find out their satisfaction level in using internet.

6. To determine their problems to use internet and web 2.0 tools.

\section{Research Methodology}

The research conducting in depth qualitative investigation alongside a survey of students of Management Science of DAVV, Indore has been made. For fulfilling this purpose Structured Questionnaire survey has been used for Primary Data Collection. There are four departments include in Management Science faculty of DAVV, ie Institute of Management Studies(IMS) International Institute of Professional Studies(IIPS), School of Future Studies and Planning (SFSP), School of Economics(ECON). For conducting survey 760 Questionnaires were distributed among the student of Department of Management Science studies of Devi Ahilya Vishwavidhyalaya, Indore 606 students have returned the filled questionnaires. Many research articles are also reviewed for secondary data collection. APA Style Manual is used for interpretation of references.

\section{Concept of Web 2.0.}

The Web 2.0 refers to the interactive, user-centred design of the World Wide Web where users not only right to use the web content but at the equal time produce the web content. The term 'Web 2.0' was coined in 1999 by Darcy DiNucci. Its increase and popularity began in 2004, when O'Reilly Media and MediaLive organized the first Web 2.0 conference.

\section{Tools of Web 2.0 and its Library use Blog}

A blog is a website, which is update regularly, post dated and set in reverse chronological classify. A blogger maintains his/her blog with various and infinite information depending upon the intention and nature of 
the blog. Everybody can read and write their views. By using blogs librarians can serve Information directly to the user with news and up to date information related to new services.

\section{Instant Messaging}

Instant messaging is an immediate text/audio/video contact among more than one individual. A number of new and future library systems integrate this useful service.

\section{Streaming Media}

Streaming media is an in order delivery of multimedia content over the network generally on request. In traditional libraries a lot of short films, music, and unusual forms of streaming media are catalogued and given to the users to be used offline.

\section{News Feeds}

News feed also known as RSS Feed. The RSS stands for Real Simple Syndication. It is a web function which facilitates automatically receive the publication of habitually updated work such as New arrivals update, e-News Paper, Podcast, news headlines, blog entries, and audio-video files in a standard format.

\section{Social Networking Sites}

Social Network Sites are full of features, which allow the user community to send e-mails, post comments, share audio and video files, take part in live chats, etc. Nowadays MySpace, Facebook, Orkut, Youtube, Flickr, Picasa, etc., social networks are very popular.

\section{Wiki's}

Wiki's are basically open web-pages, where everyone registered with the Wiki's can circulate to it, revise it, and change it. Library Wiki's as a service can permit social interaction among librarians and patrons, essentially moving the study group room online. As users share information and ask questions, answer questions, and librarians do the same.

Table:-1 Responses from the Management Science students of DAVV

\begin{tabular}{|c|l|c|c|c|}
\hline S.N. & $\begin{array}{l}\text { Name of } \\
\text { Institution }\end{array}$ & $\begin{array}{c}\text { Questionnaires } \\
\text { Distributed }\end{array}$ & Responses Received & \% of Response \\
\hline 1 & IMS & 240 & 225 & $93.75 \%$ \\
\hline 2 & IIPS & 230 & 220 & $95.65 \%$ \\
\hline 3 & IFSP & 150 & 91 & $60.66 \%$ \\
\hline 4 & SOE & 140 & 70 & $50 \%$ \\
\hline & Total & $\mathbf{7 6 0}$ & $\mathbf{6 0 6}$ & $\mathbf{7 9 . 7 3 \%}$ \\
\hline
\end{tabular}

As Discuss in the research methodology first that 690 Questionnaires were distributed in Management Science students of DAVV. There are four department have pursuing Management course in DAVV. No. of Student is different in different department so the equal no. of Questionnaire not given to the each department. Total 606 questionnaires received out of 690 questionnaires distributed. It is clear from the table that IIPS give 95\% response IMS 93.75\%, IFSP $60.66 \%$ and School of Economics student shows only 50\% response. IIPS and IMS both have a large no of students in difference courses of management sciences so the number of questionnaires and responses are more than others.

Table: 2-Awareness of students about Internet and web 2.0

\begin{tabular}{|c|l|c|c|}
\hline S.N. & Particulars & Total Response & Percentage \\
\hline 1 & Beginner. & 48 & $7.92 \%$ \\
\hline 2 & Below Average & 70 & $11.55 \%$ \\
\hline 3 & Average & 299 & $49.33 \%$ \\
\hline 4 & Expert & 189 & $31.18 \%$ \\
\hline & Total & $\mathbf{6 0 6}$ & $\mathbf{1 0 0 \%}$ \\
\hline
\end{tabular}

Internet becomes an essential part of education system. Everyone can access internet for search Information easily. By this question we find the self evaluation of the student about awareness of Internet. The table shows about Accessibility and use of internet and modern technology. It is clear from the table that out of 606 respondents, $299(49.33 \%)$ respondents feel they have average knowledge about internet, 189 (31.18\%) students feel that they have expertise knowledge in using internet, 70(11.55\%) Student put themselves as below average and $48(7.92 \%)$ students feel that they are beginner. 
Web 2.0 Technologies and its Application: A Study of Management Science students

Table-3: Per week time spend on Internet and web 2.0 by the students (per week)

\begin{tabular}{|c|l|c|c|}
\hline S.N. & Particulars & Total & Percentage \\
\hline 1 & $1-10 \mathrm{hrs}$ & 100 & $16.50 \%$ \\
\hline 2 & $11-20 \mathrm{hrs}$ & 271 & $44.71 \%$ \\
\hline 3 & $21-30 \mathrm{hrs}$ & 202 & $33.33 \%$ \\
\hline 4 & $31-40 \mathrm{hrs}$ & 33 & $5.44 \%$ \\
\hline & Total & $\mathbf{6 0 6}$ & $\mathbf{1 0 0 \%}$ \\
\hline
\end{tabular}

Time consuming is an important factor for using internet services. By this question we enable to understand the time spend on Internet by the Management Science students of DAVV. It is found that the total time spent per week on internet was average. Out of 606 respondents, 271(44.71\%) respondents use internet 11 $20 \mathrm{hrs}$ per week. While out of 606 respondents, 202(33.33\%) respondents use internet 21-30 hrs per week, $100(16.50 \%)$ respondents use internet 1-10 hrs. per week. And 33(5.44\%) respondents use internet 31-40 hrs per week. Highest categories of respondent are $44.71 \%$ with $11-20$ hours per week.

Table-4: Main reason for using Internet and web 2.0

\begin{tabular}{|c|l|l|c|c|}
\hline S.N. & Particulars & Particulars & Total & Percentage \\
\hline 1. & To update current information on subject & $1-10 \mathrm{hrs}$ & 48 & $7.92 \%$ \\
\hline 2. & More Information is available on subject & $11-20 \mathrm{hrs}$ & 70 & $11.55 \%$ \\
\hline 3. & For sharing information with friends & $21-30 \mathrm{hrs}$ & 299 & $49.33 \%$ \\
\hline 4. & Insufficient information available in Library & $31-40 \mathrm{hrs}$ & 189 & $31.1 \%$ \\
\hline & & Total & $\mathbf{6 0 6}$ & $\mathbf{1 0 0 \%}$ \\
\hline
\end{tabular}

The Internet has enabled entirely new forms of social interaction, activities, and organizing services. All types of information resources are now made available on internet ranging from all kinds of databases to Ejournals, E-book and other forms such as table of contents, preprints, technical reports, dictionary, encyclopedia, library catalogue, Institution associations, directories, newsletters etc. There are various reason to use internet by the students. The data shown from the table that out of 606 respondents, 299(49.33\%) respondents are using internet and web 2.0 for sharing information with friends and $189(31.18 \%)$ respondents are using internet due to insufficient information available in Library. 70(11.55\%) respondents use internet for more Information is available on subject and $48(7.92 \%)$ respondents are using internet for to current update in their subject.

Table-5: Awareness about Web 2.0 tools

\begin{tabular}{|c|l|l|l|l|l|}
\hline & & & & \\
S.N. & Particulars & Constantly & Sometime & Infrequently & Total \\
\hline 1. & Blogs & $324(53.46 \%)$ & $262(43.23 \%)$ & $20(3.30 \%)$ & $100 \%$ \\
\hline 2. & SNSs & $501(82.67 \%)$ & $105(17.32 \%)$ & 0 & $100 \%$ \\
\hline 3. & Wiki's & $474(78.21 \%)$ & $132(21.78 \%)$ & 0 & $100 \%$ \\
\hline I. & IM & $293(48.34 \%)$ & $263(43.39 \%)$ & $50(8.25 \%)$ & $100 \%$ \\
\hline
\end{tabular}

Web 2.0 is a popular term used to describe a Web application that offers mostly free services to its users. These Web 2.0 tools have become increasingly popular over the past few years, providing a more efficient and user-friendly way to maintain social connections and share information in different forms and mediums, such as blogs, mobile text alerts, instant messaging, and Social Networking Sites, Wiki's and RSS Feed. Data presented in the table shows that the almost all the web 2.0 tools used constantly by the management students of DAVV. It is clear from the table that Wiki's 474(78.21\%) and Social Networking Sites 501(82.67\%) is the desired tool used by the students. Blog, Instant messaging and RSS is also having good number of responses.

Table-6: Facilities on Web 2.0 like most for communication

\begin{tabular}{|l|l|l|l|l|l|}
\hline S.N. & Particulars & Constantly & Sometimes & Infrequently & Total \\
\hline 1 & Blogs & $362(59.73 \%)$ & $199(32.83 \%)$ & $45(7.42 \%)$ & $100 \%$ \\
\hline 2 & SNSs & $489(80.69 \%)$ & $105(17.32 \%)$ & $12(1.98 \%)$ & $100 \%$ \\
\hline 3 & Wikis & $471(77.72 \%)$ & $123(20.29 \%)$ & $12(1.98 \%)$ & $100 \%$ \\
\hline 4 & Discussion Lists, News groups & $262(43.23 \%)$ & $245(40.42 \%)$ & $99(16.33 \%)$ & $100 \%$ \\
\hline 5 & Chat & $534(88.11 \%)$ & $66(10.89 \%)$ & $6(0.99 \%)$ & $100 \%$ \\
\hline 6 & Instant Messaging & $247(40.75 \%)$ & $218(35.97 \%)$ & $41(6.76 \%)$ & $100 \%$ \\
\hline
\end{tabular}


Technology has not only mediated communication in countless ways, but the very ways we communicate and even the ways we talk and think about communication are changing as a result. Web 2.0 technologies provide many alternatives for communicate our thoughts like Blog, SNSs, and Wiki's, chatting and instant messaging etc. It is clear from the table that the Web 2.0 tools are the favorite form of Management students of DAVV. In these tools online chatting is mostly preferred with $88.11 \%$, SNSs with $80.69 \%$ on the second choice and Wiki's with $77.72 \%$ on third choice of the students. Search on Blogs also good no. of students' choice almost $60 \%$.

Table-7: Preferred place for accessing Web 2.0 tools

\begin{tabular}{|c|c|c|c|c|c|c|}
\hline S.N. & Particulars & Home & IT Center & College Library & Cyber & Total \\
\hline 1 & $\mathrm{~B} \log \mathrm{s}$ & $301(49.66 \%)$ & $53(8.74 \%)$ & $28(4.62 \%)$ & $224(36.96 \%)$ & $100 \%$ \\
\hline 2 & SNSs & $315(51.98 \%)$ & $33(5.44 \%)$ & $45(7.42 \%)$ & $213(35.14 \%)$ & $100 \%$ \\
\hline 3 & wikis & $267(44.05 \%)$ & $93(15.34 \%)$ & $96(15.84 \%)$ & $150(24.75 \%)$ & $100 \%$ \\
\hline 4 & RSS Feed & $200(33.00 \%)$ & $125(20.62 \%)$ & $81(13.36 \%)$ & $200(33.00 \%)$ & $100 \%$ \\
\hline 5 & $\begin{array}{l}\text { Discussion Lists, News } \\
\text { groups }\end{array}$ & $278(45.87 \%)$ & $95(15.67 \%)$ & $105(17.32 \%)$ & $128(21.12 \%)$ & $100 \%$ \\
\hline 6 & Chat & $306(50.49 \%)$ & $78(12.87 \%)$ & $72(11.88 \%)$ & $150(24.75 \%)$ & $100 \%$ \\
\hline 7 & IM & $285(47.02 \%)$ & $126(20.79 \%)$ & $24(3.96 \%) \mathrm{S}$ & $171(28.21 \%)$ & $100 \%$ \\
\hline
\end{tabular}

There are various places to accessing Web 2.0 tools. Through this question we find the favorite place for accessing these tools. Users were provided a wide range for selection like home, IT Center etc as given in the table. The table shows that student preferred places for use the web 2.0 tools for our research and study purpose. Almost all the respondents preferred home for using web 2.0 tools. Cyber café on the second and IT center of DAVV are second and third choice respectively.

Table-8: Frequency of using Internet and web 2.0 tools

\begin{tabular}{|c|l|l|l|l|l|l|}
\hline S.N. & Particulars & Daily & Weekly & Monthly & Infrequently & Total \\
\hline 1 & E-Mail & $366(60.39 \%)$ & $199(32.83 \%)$ & $19(3.13 \%)$ & $22(3.63 \%)$ & $100 \%$ \\
\hline 2 & Blogs & $260(42.90 \%)$ & $193(31.84 \%)$ & $113(18.64 \%)$ & $40(6.60 \%)$ & $100 \%$ \\
\hline 3 & SNSs & $510(84.15 \%)$ & $54(8.91 \%)$ & $36(5.94 \%)$ & $6(0.99 \%)$ & $100 \%$ \\
\hline 4 & Wikis & $359(59.24 \%)$ & $206(33.99 \%)$ & $24(3.96 \%)$ & $17(2.80 \%)$ & $100 \%$ \\
\hline & $\begin{array}{l}\text { Discussion } \\
\text { Lists, News }\end{array}$ & & & & & \\
\\
5
\end{tabular}

Frequency of use shows the influence of Internet on the students. This question helps us to observe the trustworthiness of internet among students. It is clear from the result that the respondents are using internet daily. The table shows that the various internet based services like SNSs, E-mail and Wikis are the used by students daily. More than 50\% students show response about it. The SNSs is highest preferred web 2.0 tool.

Table-9: Reason for using internet and web 2.0 for study and research

\begin{tabular}{|c|l|c|c|}
\hline S.N. & Particulars & Total Response & Percentage \\
\hline 1 & Fast research updates & 129 & $21.28 \%$ \\
\hline 2 & Fast access to databases & 87 & $14.35 \%$ \\
\hline 3 & Saving time. & 279 & $46.03 \%$ \\
\hline 4 & Update course syllabus & 111 & $18.31 \%$ \\
\hline & Total & $\mathbf{6 0 6}$ & $\mathbf{1 0 0 \%}$ \\
\hline
\end{tabular}

The Internet allows greater flexibility in working hours and location, especially with the spread of unmetered high-speed connections. The Internet can be accessed almost anywhere by numerous means, including through mobile Internet devices so student like most this service. The study found that out of $606(100 \%)$ respondents, $129(21.28 \%)$ respondents are using internet facilities for fast research updates and $87(14.35 \%)$ respondents are using internet facilities for fast access to databases and 279(46.03\%) respondents are using internet facilities for saving time and 111(18.31\%) respondents are using internet facilities for update course syllabus. So above result shows that majority of respondents for saving time.

Table-10: Problems in accessing web search engines

\begin{tabular}{|c|l|c|c|}
\hline $\mathbf{N}$ & Particulars & Particulars & Percentage \\
\hline 1 & Slow Access & 246 & $40.59 \%$ \\
\hline 2 & Difficult in retrieving & 144 & $23.76 \%$ \\
\hline 3 & Unfamiliarity with search method & 216 & $35.64 \%$ \\
\hline
\end{tabular}




\begin{tabular}{|l|l|c|c|}
\hline & Total & 606 & $100 \%$ \\
\hline
\end{tabular}

Internet is very useful for our research and study purpose. But various problems mentioned by the respondents there is unique problem that an obstacle the majority of respondents is problem are slow access of internet connection. The table shows that out of $606(100 \%)$ respondents, $246(40.59 \%)$ respondents faced problem of slow access of internet and 144(23.76\%) respondents agree for difficult in retrieving and $216(35.64 \%)$ respondents are unfamiliarity with search method.

\section{Findings}

1. Most of the Management Science faculty students (49.33\%) are using internet for sharing information to their friends, insufficient information (31.18\%) in the library is second major reason for searching on net.

2. There are various Web 2.0 tools available. But Social networking sites $(82.67 \%)$ and wikis $(78.21 \%)$ are the first and second choice among students blog (53.46\%) and other web 2.0 tools like instant messaging $(48.34 \%)$ and RSS Feed $(42.57 \%)$ have less responses.

3. Internet provides current information without any time to its users so $46.03 \%$ student shows their interest in it. $21.28 \%$ student use it for latest information.

4. Slow Access is the major problem, feel by the students. $40.59 \%$ user shows their response in this regard.

5. Unfamiliarity with search method $(35.64 \%)$ is another main reason for problem searching on net.

\section{Conclusion:-}

The study presents a general trend of Web 2.0 tools usage among the Management students of Devi Ahilya Vishwavidyalaya Indore. It was found that Web 2.0 tools like Social media, Blogs, Wikis, Instant Messaging and RSS Feed services and Social networking sites like Face book, Twitter, etc. were the most used social media sites by them. As a result the findings of this study correlate with the above studies which state that the use of social media is quickly growing between young adults and students. Although this survey is limited to a group of Management students of DAVV, the data obtained provide some insights into how students in DAVV, Indore have been using the social media for both formal and informal learning and communication.

\section{Reference}

[1]. Preeti Patel, Kishor John (2013):'Use of Social Networking sites: Users perspectives" SALIS Journal of Information And Management and technology.VOl.4 (1) Jan- June 2013, ISSN: 09754105. p.p. 51-55.

[2]. Musthafa K, Mohamed (2012). Social Networking Experience of University Student on Facebook. Eqbal, Monawwer \& Khurana, Simmi (ed.) Knowledge Management Issue and Challenges. (pp.29-37). New Delhi: World Education.

[3]. Sahi, V. S. and Veena kumari (2012). "Role of Web 2.0 Technology and Social Networking in Library: A Study of the Dahnvantri Library, University of Jammu. Eqbal, Monawwer \& Khurana, Simmi (ed.) Knowledge Management Issue and Challenges. (pp.122129). New Delhi: World Education.142-147.

[4]. Aqil, Mohammad \& Ahmad, Parvez (2011). Web 2.0 and Libraries: Facts or Myths. DESIDOC Journal of Library \& Information Technology, 31(5), pp.395-400.

[5]. Soni, Goutam. Verma, Neeraj. \& et. Al. (2010). Web 2.0 to Library 2.0 and Librarian 2.0: A Paradigm Shift. Fifty Fifth ILA National Conferences, on Library and Information Science in the Digital Era, January, 21-24 2010. ILA, (pp.21- 32). New Delhi.

[6]. Weber, Sebastian \& Rech, Jörg (2009). An Overview and Differentiation of the Evolutionary Step of the Web XY Moment: The Web before and beyond 2.0. Retrieved Oct. 9, 2011 from: http://paper.joergrech. com/BC WeberRech_WebX\%20YClassification_cameraready final.pdf.

[7]. Birdsall, William F. (2007). Web 2.0 as a Social Movement. Retrieved Nov. 22, 2011 from: http://www.webology.org/2007/v4n2/a40.html

[8]. Xiao, Norah (2008). Web 2.0 as a Catalyst: Virtual Reaching out to the user and connecting them to Library Resource and Service. Retrieved Nov. 23, 2011 from: http://www.istl.org/08-fall/article2.html.

[9]. Meness, Jack M. (2006). Library 2.0 Theory. Webology, 3(2). Retrieved on Nov. 28, 2011. From http://www.webology.org/2006/v3n2/a25.html 